\title{
Tissue Doppler Imaging and strain rate of the left atrial lateral wall: age related variations and comparison with parameters of diastolic function
}

Laura V. Argento ${ }^{1,2^{*}+}$ (D), Carolina M. Travetto ${ }^{2+}$, Maria de las M. Colicigno ${ }^{2}$, Gerardo Marambio ${ }^{1}$, Silvia Gentile ${ }^{2}$, Ana Salvati ${ }^{2,3}$, Jorge Lax ${ }^{1,3}$ and Tomás Cianciulli $i^{1,2,3,4}$

\begin{abstract}
Background: Strain Rate Imaging (SRI) is one of the most used techniques to study left atrial (LA) and diastolic function. Its availability in low-income countries is diminished since it requires additional expensive software, among other limitations. In contrast, Tissue Doppler Imaging (TDI) is widely available and easy to use. We hypothesize TDI could detect changes in LA and diastolic function associated with age similarly to SRI. The aim of this study is to evaluate the effects of age on LA and diastolic function assessed by LA lateral wall TDI online by spectral pulse, and to compare them with age-related variations of LA SRI and other parameters of diastolic function in a population of healthy adults.
\end{abstract}

Materials and methods: Ninety-one healthy adults were prospectively evaluated. In apical four - chamber view the LA lateral wall was divided in three portions. Peak velocities of basal and mid portions were measured with TDI online by spectral pulse and with SRI by speckle tracking. A first positive wave (S'la and SRS) and two negative waves (E'la and SRE, and A'la and SRA respectively) were obtained. E'la/A'la ratio and SRE/SRA ratio were analyzed. The distribution of the variables by age subgroups was described and analyzed. Correlation analyses were performed.

Results: The median age was 42 years old and 54.9\% were female. E'la/A'la showed a negative good correlation with age. E'la/A'la and SRE/SRA ratios changed from $>1$ to $<1$ in the age group of 41-50 years old, while this occurred in the group of 51-60 years old for the E/A ratio. Lateral and septal mitral annulus E' showed decrease with age and prolongation of E-wave deceleration time was observed in the age group over 61 years old.

\footnotetext{
* Correspondence: vaninaargento@yahoo.com.ar

Name of the department and the institution to which the work is attributed: Echocardiography Service. Hospital General de Agudos Dr. Cosme Argerich.

†Laura V. Argento and Carolina M. Travetto contributed equally to this work.

${ }^{1}$ Hospital General de Agudos Dr. Cosme Argerich, Pi y Margall 750

(C1155AHD) CABA, Buenos Aires, Argentina

${ }^{2}$ Sanatorio Clínica Modelo de Modelo de Morón, Buenos Aires, Argentina

Full list of author information is available at the end of the article
}

(c) The Author(s). 2020 Open Access This article is licensed under a Creative Commons Attribution 4.0 International License, which permits use, sharing, adaptation, distribution and reproduction in any medium or format, as long as you give appropriate credit to the original author(s) and the source, provide a link to the Creative Commons licence, and indicate if changes were made. The images or other third party material in this article are included in the article's Creative Commons licence, unless indicated otherwise in a credit line to the material. If material is not included in the article's Creative Commons licence and your intended use is not permitted by statutory regulation or exceeds the permitted use, you will need to obtain permission directly from the copyright holder. To view a copy of this licence, visit http://creativecommons.org/licenses/by/4.0/ The Creative Commons Public Domain Dedication waiver (http://creativecommons.org/publicdomain/zero/1.0/) applies to the data made available in this article, unless otherwise stated in a credit line to the data. 
(Continued from previous page)

Conclusion: Normal values according to age group of TDI of the LA lateral wall were obtained. Age-related changes in LA and diastolic function could be detected as early with TDI as with SRI. Future studies are required to explore if this method could be used to address in part LA or diastolic function in other populations with established cardiovascular disease or at risk of presenting it, which could be useful in low-income settings, where $\mathrm{SRI}$ is not available.

Keywords: Diastolic function; tissue Doppler echocardiography, Strain rate imaging, Left atrium

\section{Background}

With senescence, a series of changes occur at the myocyte level, which results in a reduction of left ventricular (LV) distensibility and, consequently, at the atrial level in a decrease in the conduit phase and a compensatory increase of LV filling during atrial systole [1-4].

Several studies have shown an association between atrial and diastolic dysfunction and the development of cardiovascular events during follow up, particularly atrial fibrillation (AF) [5-8] and heart failure in patients with preserved LV systolic function [9-11].

The evaluation of the left atrium (LA) by Echo Doppler is in expansion; new techniques have been developed in recent years, including Tissue Doppler Imaging (TDI) and Strain Rate Imaging (SRI). Impaired atrial function detected by SRI has been associated with adverse cardiovascular events [12, 13].

The evaluation of atrial and diastolic function by SRI can be a challenge in low-income countries or centers since it requires using additional expensive software, among other limitations. On the other hand, TDI is a simple technique and is currently widely available.

Previously, we have reported the associations observed between the velocity profile of LA lateral wall measured by TDI online by spectral pulse with atrial SRI by speckle tracking, and other parameters of atrial and diastolic function, in a population of adults without known cardiovascular disease [14]. This report consists of a sub-analysis of that study and seeks to describe the agerelated variations observed in the parameters analyzed in a normal population, in order to establish an initial reference value necessary, as a previous instance, for the study of atrial and diastolic function through this method in other populations with established cardiovascular pathology or at risk of presenting it.

\section{Materials and methods}

The aim of this study is to evaluate the effects of age on LA and diastolic function assessed by LA TDI online by spectral pulse, and to compare them with age-related variations of LA SRI and parameters of diastolic function in a population of healthy adults.

As previously reported, 91 healthy adults, aged between 18 and 74 years old, were prospectively evaluated in two health centers between April 2016 and March 2018. None of the subjects had a known history of cardiovascular disease, high blood pressure, dyslipidemia, diabetes, electrocardiographic alterations or was under cardiovascular medical treatment. A complete color Doppler echocardiogram was performed.

\section{Echocardiogram and cardiac Doppler}

An ultrasound machine Vivid S5 or 7 (GE Medical System, Horten, Norway), equipped with a $3 \mathrm{MHz}$ variable frequency transducer, was used for all of the echocardiographic evaluations. Cardiac diameters were measured according to the recommendations of the ASE [15]. The $M$ mode was used to measure the diameters of LA and LV. Volumes of LA were measured in a single-plane apical four-chamber view, using the method of discs.

Transmitral flow velocities were obtained by pulsed wave Doppler echocardiography, in an apical fourchamber view. Mitral flow parameters measured included peak velocities during early diastole (E) and late diastole (A), their ratio (E/A ratio), and E-wave deceleration time (DTE).

TDI online by spectral pulse of the septal and lateral mitral annulus was performed, and peak of the systolic wave $S^{\prime}$ (Sma $S^{\prime}$, Lma $S^{\prime}$ ), early filling wave E' (Sma E', Lma $\left.E^{\prime}\right)$ and late filling wave $A^{\prime}$ (Sma $A^{\prime}$, Lma $A^{\prime}$ ) were measured. The E/e' average ratio was calculated.

Parameters used to define normal diastolic function were: Lma E'> $10 \mathrm{~cm} / \mathrm{s}$, Sma E'> $7 \mathrm{~cm} / \mathrm{s}$, average E/e'< 14 , peak velocity of tricuspid regurgitation $<2.8 \mathrm{~m} / \mathrm{s}$, LA volume indexed $<34 \mathrm{ml} / \mathrm{m}^{2}$ [16].

For the analysis of LA function by TDI and SRI, lateral wall was obtained in the apical four chamber view and divided subjectively into three portions: basal segment, mid segment and atrial roof (Fig. 1a). TDI by spectral pulse measures were taken online, in apnea, at the end of expiration, with a sample volume of $2 \mathrm{~mm}$ and trying to maintain an angle less than $15^{\circ}$; gain and filter were adjusted to avoid saturation of the image. Three consecutive measurements of basal and mid segments were performed and the best spectral image of each segment was selected for the analysis; and peak velocities of this waves were measured, the atrial roof was excluded from the measurements. 


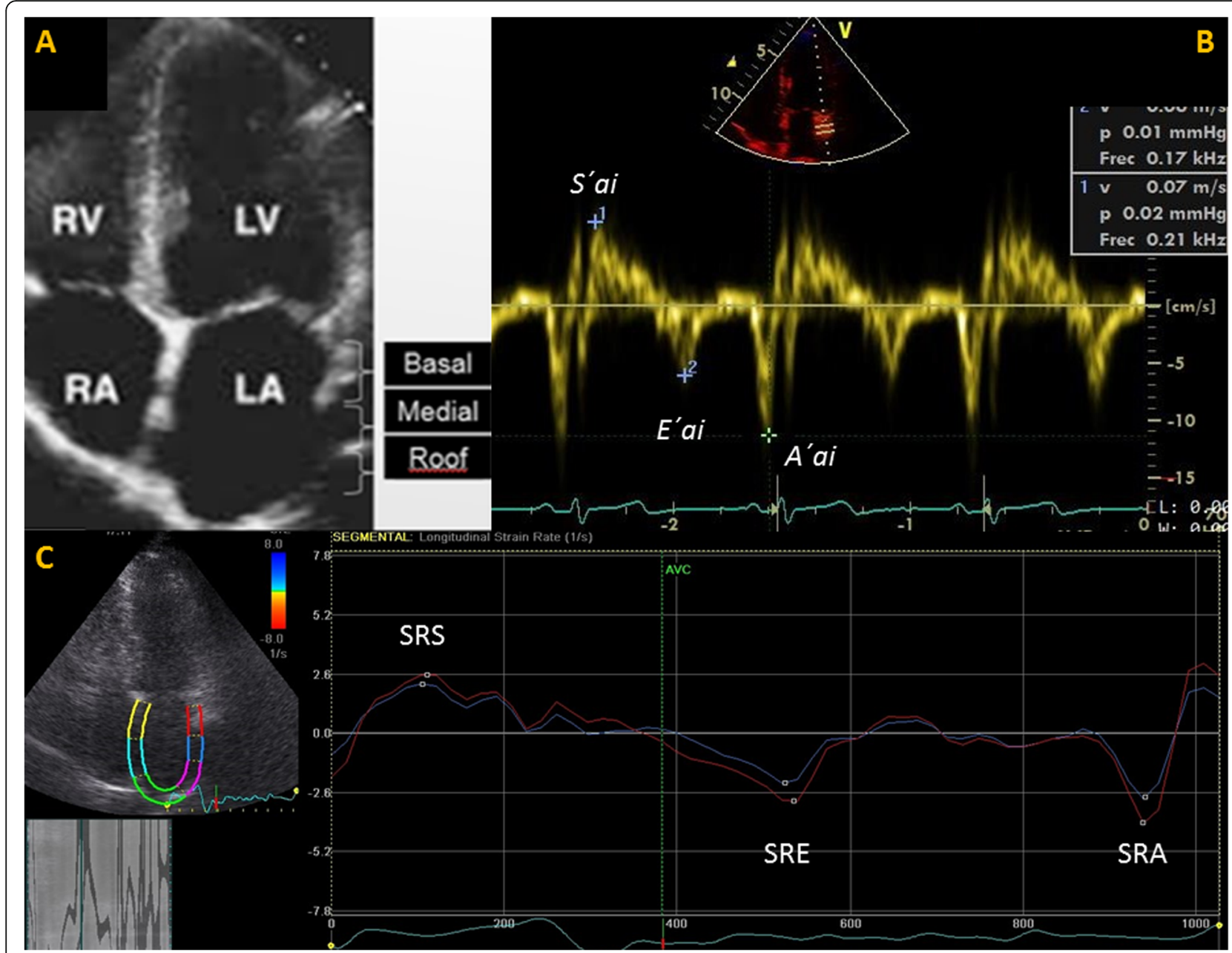

Fig. 1 Methodology used for the evaluation of LA lateral wall by TDI and SRI. A) Subjective division of the LA lateral wall in three segments; B) TDI on line by spectral pulse at basal segment of LA lateral wall. Three waves are identified: S'la (evaluates reservoir function), E'la (evaluates conduit function), $A^{\prime \prime l}$ (evaluates pump function). C) LA SRI by speckle tracking with the analysis of the basal and mid segments. Three waves are identified: SRS (evaluates reservoir function); SRE (evaluates conduit function) and SRA (evaluates pump function). For more information, refer to the text. LA: left atrial, TDI: Tissue Doppler Image, SRI: Strain Rate Image, la: left atrial

The Echo Pac software v 108.1.5 (GE Healthcare) was used for the analysis of two-dimensional SRI by speckle tracking. In an apical four-chamber view, the endocardial surface of the LA was manually drawn, using a single cardiac cycle and the $\mathrm{R}$ wave as a reference point. A region of interest was automatically generated, and manually tracked, frame by frame, to maintain its position within the LA wall, to ensure that the regions of interest would follow the cardiac movement throughout cardiac cycle. The LA was divided into six segments automatically; the limits of the basal and mid segments of the lateral wall of the LA were manually adjusted to resemble the division made by TDI, excluding the atrial roof and the remaining segments. All the images were obtained at an average frame rate of $63+/-6$.

With both techniques, TDI and SRI, three waves were obtained: a first positive wave, S'la and SRS (reservoir phase), and two negative waves, E'la and SRE (conduit phase) and A'la and SRA (atrial systole) respectively (Fig. 1b and c). The ratios between E'la/ $A^{\prime} l a$ and SRE/SRA were analyzed. Basal and mid segments were analyzed, as well as the average between basal and mid segments when both curves could be measured. Segments that did not have adequate image quality were excluded from the analysis. Likewise other authors [17], we did not include the interatrial septum since it is very thin and largely made up of collagen tissue.

\section{Repeatability and reproducibility}

In 30 randomly selected subjects TDI measurements were performed independently and blindly by two operators, with a difference of $10 \mathrm{~min}$ between studies. Repeatability was evaluated by comparing the first two 
measurements performed by the first operator; reproducibility was evaluated by comparing the first measurement of each of the operators. Although the average of the multiple measures performed by each operator would inform lower values of variability, comparison of a single measurement was chosen for external validity reasons, given that in clinical practice the operator would not be expected to make multiple measurements and average them for report.

\section{Statistical analysis}

Absolute frequency and percentage were used as frequency measures for qualitative variables; median $(\mathrm{Md})$ and interquartile range (IQR) were used as frequency and dispersion measures for quantitative variables, given that the variables under study did not present normal distribution. We analyzed the distribution of the variables in the total population and by subgroups of age $(<$ $30,31-40,41-50,51-60$ and $\geq 61$ years). The comparisons between subgroups of age were performed with the Kruskal-Wallis method. Considering age as a continuous variable, correlation analyzes were performed to evaluate the existence of linear association between age and various parameters, using Spearman's correlation method with Holm's method adjustment. After log transformation of the abnormally distributed variables, univariable and multivariable linear regression analyzes were performed to assess association between TDI parameters and clinical predictors. Variables associated in univariate analyses were entered in multivariable models. Intra and inter-observer variabilities were assessed using the Bland-Altman method, and presented as mean difference (MD), standard deviation (SD) and coefficient of repeatability (COR), calculated as $2 \times$ SD of the differences in repeated measurements [18]. In the hypothesis tests a statistical significance level of 0.05 was used, rejecting the null hypothesis if the $p$-value was lower than this level. All data analysis was performed using R Core Team 2018 software (R: A language and environment for statistical computing, $\mathrm{R}$ Foundation for Statistical Computing, Vienna, Austria. URL https://www.R-project.org/).

\section{Results}

\section{Clinical characteristics and echocardiographic measures}

\section{of the study population according to age subgroups}

The Md age was 42 years old (IQR 18 ) and $54.9 \%$ of the subjects were female. An adequate spectral signal was obtained in 99 and $92 \%$ of the basal and mid segments with TDI and in 90 and $84 \%$ with SRI, respectively. Table 1 shows the global values and the distribution of the variables according to age subgroups (data of TDI and SRI correspond to the basal segments; the values of mid segments and average between of basal and mid segments are presented in Supplemental Table 1). The older age subgroups presented higher values of systolic and diastolic blood pressure (SBP and DBP). No differences were observed between the subgroups in other clinical variables evaluated. Of the diastolic function parameters evaluated, progressive reduction of $\mathrm{E}$ wave values and parallel increase in A wave values were observed at increasing age, with reversal of the E/A ratio in the subgroups older than 50 years old. Age-related DTE prolongation $>240 \mathrm{~ms}$, reduction of Sma $\mathrm{E}^{\prime}$ and $\mathrm{Lma} \mathrm{E}^{\prime}$ waves, and increase of Sma $\mathrm{A}^{\prime}$ and $\mathrm{Lma}^{\mathrm{A}^{\prime}}$ waves were also observed. Sma $E^{\prime} / S m a A^{\prime}$ turned $<1$ in age subgroups over 50 years old and Lma $E^{\prime} / L_{m a ~} A^{\prime}$ turned $<1$ in age subgroups over 60 years old. Sma $E^{\prime}$ and Lma $E^{\prime}$ presented values below $10 \mathrm{~cm} / \mathrm{s}$ and $7 \mathrm{~cm} / \mathrm{s}$, respectively, in the subgroups over 60 years old. The $\mathrm{E} / \mathrm{e}^{\prime}$ ratio increased with age, with the Md in all groups being less than 10 .

No age related changes were observed in S'la wave at the basal segments, unlike that observed with SRS, which presented lower values at increasing age. Both E'la and SRE presented progressive variations with age, with a reduction in E'la values and an increase in SRE values in the older age subgroups. A'la wave values presented significant differences between the age subgroups, and no significant differences were observed between the groups in the distribution of SRA. E'la/A'la and SRE/SRA ratios $<1$ were found in age subgroups over 40 years old (Table 1 , Fig. 2). Similar findings were observed when analyzing mid segments and the average between basal and mid segments (Supplemental Table 1).

\section{Associations observed between age, clinical characteristics and echocardiographic measures}

Table 2 and Fig. 3 present the results of the age correlations analyzed. SBP, A wave, E/e' ratio and SRE basal presented a positive correlation with age, while Sma $E^{\prime}$, Lma E', E/A, Sma E'/Sma A', Lma E'/Lma A', E'la, SRS (mid and average), E'la/A'la and SRE/SRA at basal segments were negatively correlated; similar correlations with age were found at mid and average segments (Supplemental Table 2).

\section{Associations observed between TDI measures and clinical characteristics \\ Univariable and multivariable linear regression models for clinical predictors of LA TDI are summarized in Supplemental Table 3. Age was the most important in- dependent predictor of E'la basal, A'la basal y E'la/A'la basal.}

\section{Repeatability and reproducibility}

Table 3 shows the intra-observer and inter-observer variabilities of LA TDI. Bland-Altman analysis showed no evidence of any systematic difference regarding intra 
Table 1 Global parameters and analysis of the variables by age subgroups

\begin{tabular}{|c|c|c|c|c|c|c|c|}
\hline & $\begin{array}{l}\text { Global } \\
\text { Md (IQR) }\end{array}$ & $\begin{array}{l}\leq 30 \text { y } \\
\text { n: } 14 \\
\text { Md (IQR) }\end{array}$ & $\begin{array}{l}31-40 \text { y } \\
\text { n: } 27 \\
\text { Md (IQR) }\end{array}$ & $\begin{array}{l}41-50 \text { y } \\
\text { n: } 27 \\
\text { Md (IQR) }\end{array}$ & $\begin{array}{l}51-60 \text { y } \\
\text { n:14 } \\
\text { Md (IQR) }\end{array}$ & $\begin{array}{l}\geq 61 \text { y } \\
\text { n: } 9 \\
\text { Md (IQR) }\end{array}$ & $p$ \\
\hline Age (y) & $42(18)$ & $23.5(3.7)$ & $34(3.5)$ & $44(4)$ & $53.5(5.7)$ & $69(2)$ & $<0.0001$ \\
\hline Female (\%) & 54.9 & 64.3 & 33.3 & 63 & 64.3 & 66.7 & NS \\
\hline HR (bpm) & $74(15)$ & 76.5 (11.7) & $74(15)$ & $75(14.2)$ & $69.5(9.7)$ & $77(12)$ & NS \\
\hline SBP (mmHg) & $110.5(16.5)$ & $95(18)$ & $110(19)$ & $115(16)$ & $115(17.5)$ & $126(8.7)$ & $<0.0001$ \\
\hline DBP (mmHg) & $70.5(10)$ & $60(10)$ & $75(10)$ & $76(10)$ & $80(10)$ & $77.5(10)$ & 0.001 \\
\hline BSA & $1.83(0.2)$ & $1.71(0.1)$ & $1.97(0.3)$ & $1.83(0.19)$ & $1.84(0.4)$ & $1.76(0.1)$ & 0.03 \\
\hline EF (\%) & $63(11.7)$ & $61(8)$ & $63(13.5)$ & $66(11)$ & $62(7)$ & $62.5(12.2)$ & NS \\
\hline LA Vol Ind (ml/m2) & $22.9(8)$ & $20.6(6.3)$ & $21.7(5.4)$ & $23(12.4)$ & $25.2(5.5)$ & $22.8(3.8)$ & NS \\
\hline$E(\mathrm{~cm} / \mathrm{s})$ & $79(22.5)$ & $84.5(15)$ & $80(23.5)$ & $80(17.5)$ & $72.5(20.5)$ & $60(11)$ & 0.01 \\
\hline$A(\mathrm{~cm} / \mathrm{s})$ & $61(23.5)$ & $47.5(15.2)$ & $52(14)$ & $64(20)$ & $80(17.7)$ & $78(20)$ & $<0.0001$ \\
\hline$E / A$ & $1.32(0.7)$ & $1.79(0.7)$ & $1.62(0.4)$ & $1.22(0.5)$ & $0.98(0.3)$ & $0.7(0.3)$ & $<0.0001$ \\
\hline DTE (ms) & $211(70.5)$ & $201.5(68)$ & $190(44)$ & $202(63)$ & $228.5(45)$ & $292(152)$ & 0.003 \\
\hline $\operatorname{LmaS}^{\prime}(\mathrm{cm} / \mathrm{s})$ & $10(3)$ & $11(2.7)$ & $11(4.5)$ & $11(4)$ & $9(2.5)$ & $10(3)$ & NS \\
\hline $\operatorname{LmaE}^{\prime}(\mathrm{cm} / \mathrm{s})$ & $14(7)$ & $17.5(1.7)$ & $16(5)$ & $14(4.5)$ & $11(3)$ & $9(2)$ & $<0.0001$ \\
\hline $\mathrm{LmaA}^{\prime}(\mathrm{cm} / \mathrm{s})$ & $9(4)$ & $6.5(3.7)$ & $8(2.5)$ & $9(3.5)$ & $9.5(2.7)$ & $13(4)$ & 0.001 \\
\hline LmaE'/LmaA' & $1.70(1.12)$ & $2.70(2.48)$ & $2.0(1.09)$ & $1.37(0.65)$ & $1.10(0.57)$ & $0.6(0.37)$ & $<0.0001$ \\
\hline$S^{\prime} m a S^{\prime}(\mathrm{cm} / \mathrm{s})$ & $8(2)$ & $7(1)$ & $8(1)$ & $8(2)$ & $7.5(1)$ & $8(1)$ & NS \\
\hline Sma E' $(\mathrm{cm} / \mathrm{s})$ & $9(4)$ & $11(3.5)$ & $11(5)$ & $9(3)$ & $8(2.7)$ & $6(2)$ & 0.001 \\
\hline Sma $A^{\prime}(\mathrm{cm} / \mathrm{s})$ & $9(3)$ & $7(2)$ & $8(3.5)$ & $9(3)$ & $9(1)$ & $11(3)$ & 0.001 \\
\hline Sma E'/Sma A' & $1.11(0.81)$ & $1.73(0.49)$ & $1.37(0.92)$ & $1(0.39)$ & $0.88(0.31)$ & $0.57(0.18)$ & $<0.0001$ \\
\hline$E / e^{\prime}$ & $6.7(1.7)$ & $5.77(1.3)$ & $6.17(1)$ & $7.01(1.5)$ & $7.68(2.4)$ & $8.4(1.7)$ & 0.0002 \\
\hline$S^{\prime} l a(\mathrm{~cm} / \mathrm{s})$ basal & $11.5(3)$ & $10(2)$ & $11(2)$ & $12(3)$ & $11(3.7)$ & $12(3)$ & NS \\
\hline$E^{\prime} l a(\mathrm{~cm} / \mathrm{s})$ basal & $13(5)$ & $15(5)$ & $16(3)$ & $13(3)$ & $10(2)$ & $9(1)$ & $<0.0001$ \\
\hline$A^{\prime} l a(\mathrm{~cm} / \mathrm{s})$ basal & $12(4)$ & $10(3)$ & $11(2)$ & $14(5)$ & $12.5(2.7)$ & $13(2)$ & 0.0006 \\
\hline E'la/A'la basal & $1.06(0.6)$ & $1.63(0.5)$ & $1.42(0.4)$ & $0.92(0.2)$ & $0.82(0.2)$ & $0.64(0.1)$ & $<0.0001$ \\
\hline SRS (1/s) basal & $2.9(0.9)$ & $3.6(1.2)$ & $3.13(0.8)$ & $2.62(1.1)$ & $2.54(0.8)$ & $2.17(1.1)$ & 0.016 \\
\hline SRE (1/s) basal & $-2.74(1.1)$ & $-3.4(1)$ & $-3.06(0.6)$ & $-2.26(1.2)$ & $-2.31(0.5)$ & $-1.97(0.2)$ & $<0.0001$ \\
\hline SRA (1/s) basal & $-2.65(1.1)$ & $-2.6(1.2)$ & $-2.48(1.1)$ & $-2.7(1.1)$ & $-2.9(0.8)$ & $-2.87(0.7)$ & NS \\
\hline SRE/SRA basal & $1.03(0.6)$ & $1.23(0.1)$ & $1.19(0.5)$ & $0.78(0.6)$ & $0.88(0.2)$ & $0.69(0.1)$ & 0.002 \\
\hline
\end{tabular}

$H R$ heart rate, $b p m$ beats per minute, $S B P$ systolic blood pressure, DBP diastolic blood pressure, $B S A$ body surface area, $E F$ ejection fraction, $L A$ Vol Ind indexed left atrial volume, DTE E-wave deceleration time, Lma lateral mitral annulus, Sma septal mitral annulus, la left atrial, SR Strain Rate

or inter-observer variabilities. Greater variability was observed in the measurements of the mid segments, compared to the measurements of the basal segments.

\section{Discussion}

During the cardiac cycle the LA plays the functions of reservoir, conduit and atrial pump; the different phases are influenced by changes at the atrial chamber and the left ventricular chamber $[2,19]$.

Cell remodeling will occurs with normal aging, with loss of cardiomyocytes and compensatory development of hypertrophy; changes in the extracellular matrix were also described, with greater presence of fibrosis and deposits of amyloid protein [20]. At the molecular level, mitochondrial dysfunction and oxidative stress occur, as well as alterations in the entrance of calcium to the sarcoplasmic reticulum, which determine changes in cell elasticity with decreased relaxation and lower suction force by the LV, decrease in passive ventricular filling, and compensatory increase of the contribution of the atrial systole to LV filling to maintain an adequate stroke volume [21-23]. These events were associated with greater predisposition to suffer AF, and heart failure with preserved systolic function [24], entities that are becoming more prevalent in Argentina and the rest of the world [3, 25-28], given the increase in longevity that the world population is experiencing $[2,10]$. 


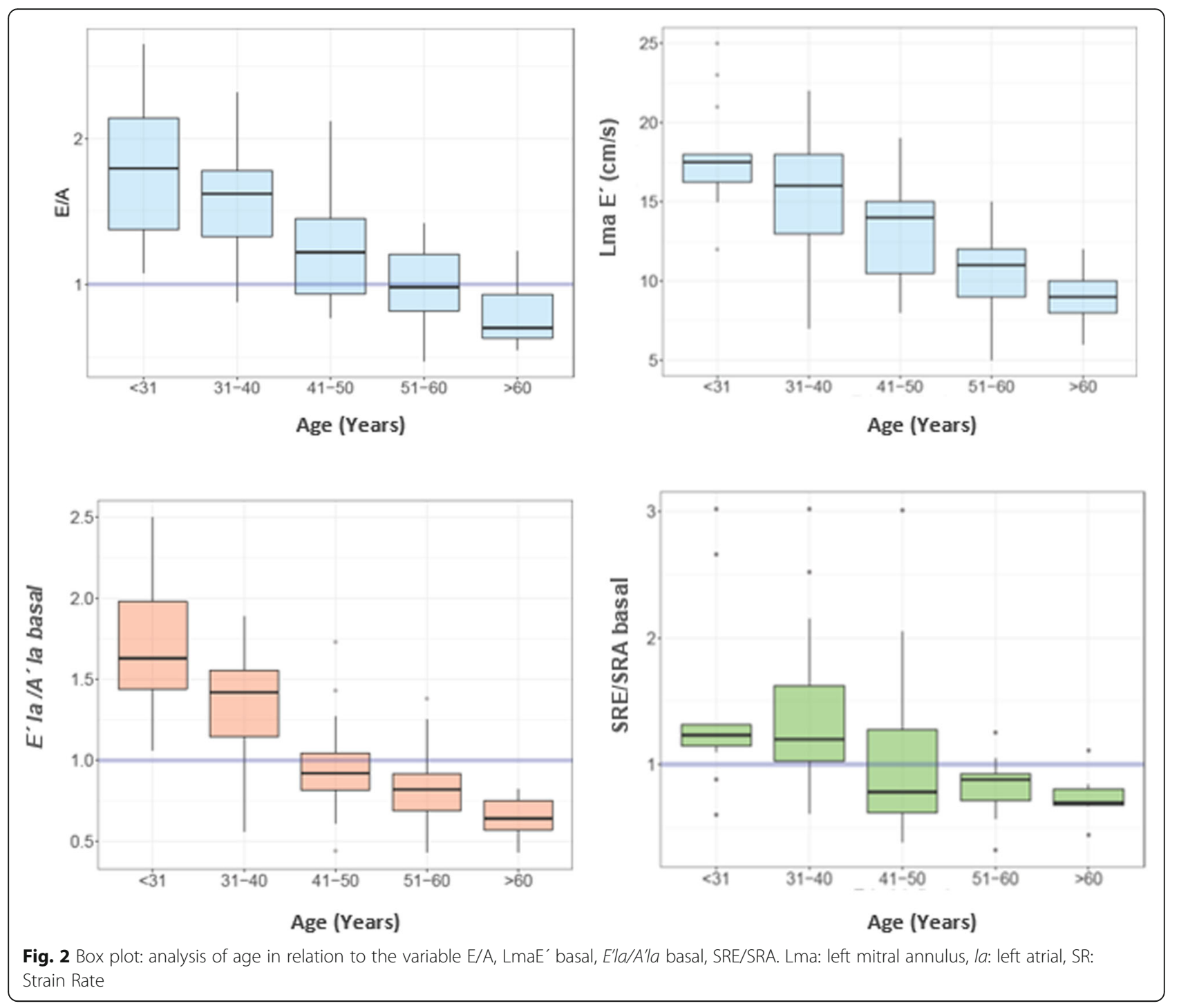

New technologies in medicine are important components of health care, have the potential to save lives and improve quality of life and well-being. However, too many people around the world do not have access to affordable and high-quality health technology, and the problem is more serious in low and middle-income countries [29].

Different authors found an association between cardiovascular events and alteration in LA function evaluated by Strain and SRI. Inaba et al. found that SRS, SRE and SRA were lower in AF patients than in age-matched controls [30]. Wang et al. found that LA SRE and LA dimension were independent predictors of cardiovascular failure [31]. Mondillo et al. found that reservoir and conduit phases were lower in patients with hypertension or diabetes than in controls [32].

Many echo laboratories do not have the possibility of assessing LA by strain since it requires additional and expensive software, as well as a wide learning curve and post-processing of the images. Unlike SRI, TDI is a simple and widely available method that allows analyzing the information at the time of the study and does not require an extensive learning curve. This led us to think it could be used, to assess LA and diastolic function in low-resource centers where SRI is not available.

As a previous instance for the study of LA and diastolic function through this method in individuals with established cardiovascular pathology or at higher risk of presenting it, we need to understand how these parameters behave in a normal population and stablish initial reference values according to age groups, which is the reason why we perform this sub-analysis.

In this study we described the age-related changes observed in a population of adults without cardiovascular disease with TDI online, SRI and other diastolic function parameters. The variations in the velocities of E'la and 
Table 2 Correlations with age

\begin{tabular}{|c|c|c|}
\hline Parameter & $R$ & $P$ \\
\hline LA Volume Indexed (ml/m2) & 0.18 & NS \\
\hline SBP $(\mathrm{mmHg})$ & 0.44 & 0.04 \\
\hline $\mathrm{DBP}(\mathrm{mmHg})$ & 0.35 & NS \\
\hline$E(\mathrm{~cm} / \mathrm{s})$ & -0.39 & NS \\
\hline $\mathrm{A}(\mathrm{cm} / \mathrm{s})$ & 0.63 & $<0.0001$ \\
\hline$E / A$ & -0.69 & $<0.0001$ \\
\hline DTE (ms) & 0.31 & NS \\
\hline$E / e^{\prime}$ & 0.47 & 0.002 \\
\hline Lma S' (cm/s) & -0.26 & NS \\
\hline Lma $E^{\prime}(\mathrm{cm} / \mathrm{s})$ & -0.69 & $<0.0001$ \\
\hline $\operatorname{Lma} A^{\prime}(\mathrm{cm} / \mathrm{s})$ & 0.40 & NS \\
\hline Lma E'/Lma $A^{\prime}$ & $-0,62$ & $<0.0001$ \\
\hline Sma S' (cm/s) & -0.12 & NS \\
\hline Sma E' (cm/s) & -0.47 & 0.002 \\
\hline Sma $A^{\prime}(\mathrm{cm} / \mathrm{s})$ & 0.34 & NS \\
\hline Sma E'/Sma A' & $-0,53$ & $<0.0001$ \\
\hline $\mathrm{S}^{\prime \prime} \mathrm{la}(\mathrm{cm} / \mathrm{s})$ basal & $-0,01$ & NS \\
\hline$E^{\prime \prime} a(\mathrm{~cm} / \mathrm{s})$ basal & -0.65 & $<0.0001$ \\
\hline$A^{\prime} l a(\mathrm{~cm} / \mathrm{s})$ basal & 0.36 & NS \\
\hline E'la/A'la basal & -0.73 & $<0.0001$ \\
\hline SRS (1/s) basal & -0.39 & NS \\
\hline SRE (1/s) basal & 0.61 & $<0.0001$ \\
\hline SRA (1/s) basal & -0.06 & NS \\
\hline SRE/SRA basal & -0.48 & 0.007 \\
\hline
\end{tabular}

LA left atrial, SBP systolic blood pressure, DBP diastolic blood pressure, DTE Ewave deceleration time, Lma lateral mitral annulus, Sma septal mitral annulus, la left atrial, $S R$ strain Rate

SRE waves, and E'la/A'la and SRE/SRA ratios identified earlier the increase in the atrial systole contribution to LV filling than other diastolic function parameters.

\section{Comparison with previous studies}

Pérez Paredes et al. [17] studied LA lateral wall with TDI by spectral pulsed online in mid segments, finding a decrease in the early diastole wave and an increase in late diastole wave in the age group over 45 years old; no changes in the reservoir phase were reported. Similar results were also obtained by Thomas et al. [33] when evaluating late diastole wave of the LA lateral wall at the annular and mid segments levels with color TDI offline.

As shown in Fig. 4, in the present study, when comparing the results obtained at the annular and auricular levels by TDI, we observed that LA lateral wall has a different speed profile from the mitral annulus; while E'la/ A'la ratio turned $<1$ in the age-group older than 40 years old, Lma $E^{\prime} / L m a A^{\prime}$ ratio changed in the sixth decade, which suggests that by directly assessing the atrial myocardium we can detect changes that are not evident at the annulus level.

Inaba et al. evaluated the LA by SRI in a subgroup of healthy patients; they could not find a significant correlation of late diastole with age, which according to the author could be due to the quality of images and having analyzed only one of the walls [30]. Boyd et al. also evaluated a population of healthy adults with atrial SRI and reported significant correlation of SRI with age at the different phases: reservoir, conduit and atrial systole [1]. Similar findings were reported by Sun et al.; this author analyzed the ratio between early and late diastole (SRE/SRA) finding a negative correlation with age. These authors also demonstrated changes in atrial SRI that would allow earlier detection of impaired diastolic function with this method compare to other parameters usually used [34].

In a recent work Yoshida et al. evaluated the impact of age on cardiac function by speckle tracking SRI echocardiography and serum B type natriuretic peptide and concluded that the decrease in the reservoir and conduit phases are the earliest markers of age-related cardiac remodeling [35]. Regarding the atrial contraction function and its changes with age, the information is still controversial; some studies showed an increase in this function [20,24] while others did not find significant changes $[28,33,36]$.

In this study both TDI and SRI showed a modification in the velocities of the LA lateral wall in the age subgroups over 40 years old, at least a decade before the other methods analyzed.

Regarding reproducibility, Thorstensen et al. evaluated inter-observer variability of Lma $S^{\prime}$ and Lma $E^{\prime}$ by pulsed wave TDI and reported inter-observer COR of $2.1 \mathrm{~cm} / \mathrm{s}$ and $5.5 \mathrm{~cm} / \mathrm{s}$, respectively, which are comparable to those observed in this study for S'la basal and E'la basal (COR $3.12 \mathrm{~cm} / \mathrm{s}$ and COR $3.7 \mathrm{~cm} / \mathrm{s}$ ). The COR of Lma $\mathrm{A}^{\prime}$ was not reported in that study; instead, they reported a COR of $2.1 \mathrm{~cm} / \mathrm{s}$ for the average value of $\mathrm{mi}-$ tral annulus $\mathrm{A}^{\prime}$ measured at the septal, lateral, inferior and anterior walls, which is inferior to the A'la basal COR of $3.82 \mathrm{~cm} / \mathrm{s}$ observed in this study, as expected, since the authors reported that averaging measures of multiple walls resulted in a reduction of the error [37].

Thomas et al., who evaluated the LA lateral wall by TDI offline, reported an intra-observer mean difference of $0.06 \mathrm{~cm} / \mathrm{s}$ with $95 \%$ limits of agreement between 0.42 and $-0.3 \mathrm{~cm} / \mathrm{s}$, and inter-observer mean difference of $0.07 \mathrm{~cm} / \mathrm{s}$ with $95 \%$ limits of agreement between 0.61 and $-0.47 \mathrm{~cm} / \mathrm{s}$ for A'la values measured at mid segments [33]. As the Hunt study showed, assessing variability by comparing repeated offline analyzes of the same recording previously acquired results in smaller values of variability of each parameter analyzed. For instance, the authors described that inter and intraanalyzer average mean error for the global diastolic 


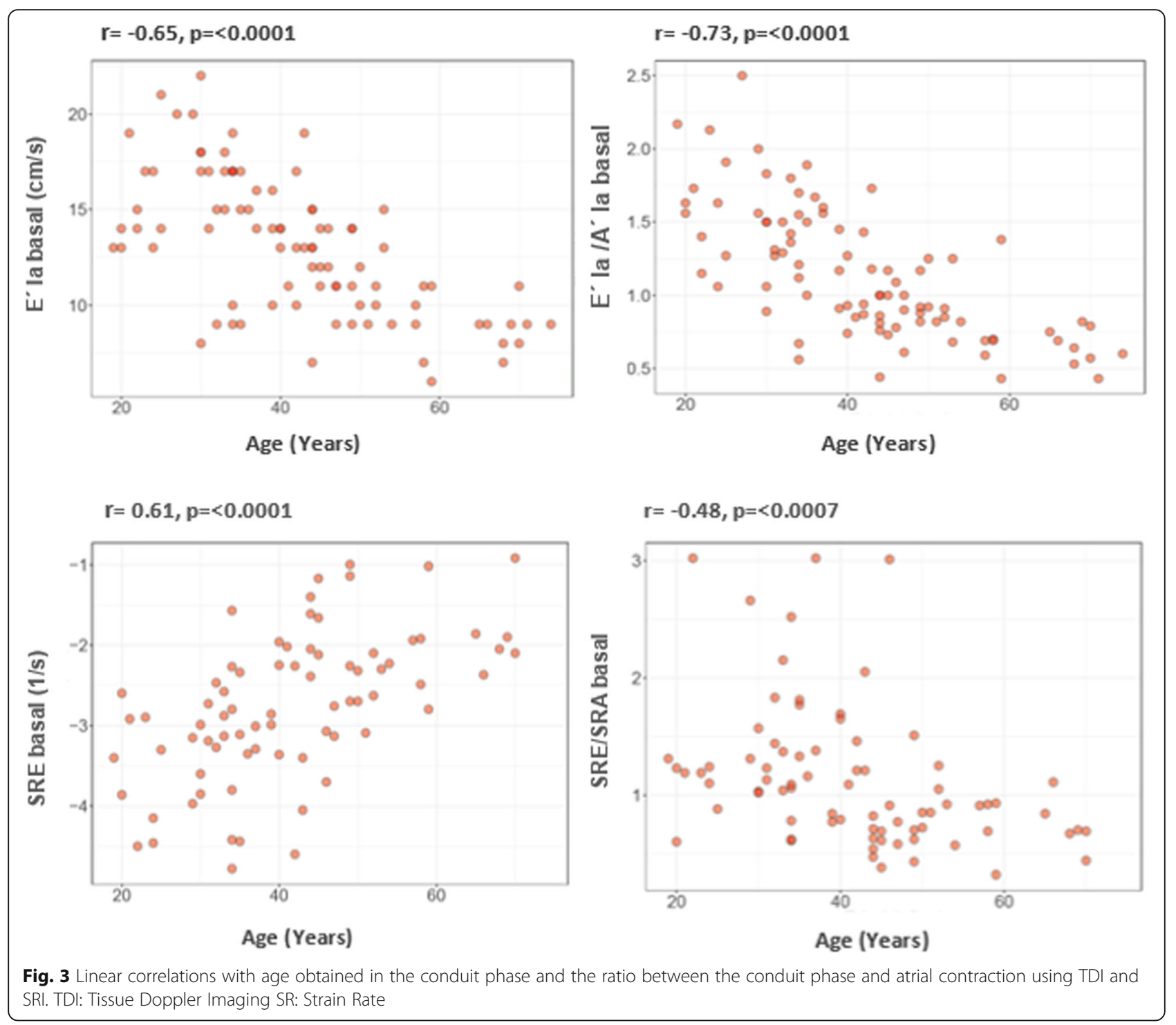

Table 3 Intra-observer and inter-observer variabilities of LA TDI

\begin{tabular}{llllll}
\hline Variable & \multicolumn{2}{l}{ INTRA-OBSERVER } & & \multicolumn{2}{l}{ INTER-OBSERVER } \\
\cline { 2 - 3 } & MD $\pm \mathrm{SD}$ & $\mathrm{COR}$ & & $\mathrm{MD} \pm \mathrm{SD}$ & $\mathrm{COR}$ \\
\hline S'la basal & $0.06 \pm 1.01$ & 2.02 & & $0.56 \pm 1.56$ & 3.12 \\
E'la basal & $0.16 \pm 1.01$ & 2.02 & & $-0.26 \pm 1.85$ & 3.7 \\
A'la basal & $0.03 \pm 1.21$ & 2.42 & & $0.2 \pm 1.91$ & 3.82 \\
S'la mid & $0.16 \pm 1.28$ & 2.56 & & $0.9 \pm 1.9$ & 3.8 \\
E'la mid & $0.06 \pm 1.41$ & 2.82 & & $0.53 \pm 2.52$ & 5.04 \\
A'la mid & $0.1 \pm 1.39$ & 2.78 & & $0.06 \pm 2.21$ & 4.42
\end{tabular}

$M D$ mean difference, $S D$ standard deviation, COR coefficient of repeatability, la left atrial measurements was 44 and $64 \%$ lower than the average mean error calculated by separate recordings and analyses. This highlights the influence of the image acquisition process on intra e inter-observer variability, and could be a possible explanation for the differences observed between this study and that of Thomas et al.

\section{Limitations}

The main disadvantage of the TDI by spectral pulse online is that measurements are dependent on the insonation angle and can subject to translational movement of adjacent structures [38-41]. To overcome these limitations, in this study the measurements were made trying to maintain the narrowest possible angle of the segments to be measured, with a small sample volume and in expiratory apnea. We also evaluated and compared the results obtained at the basal and mid segments, and the average 


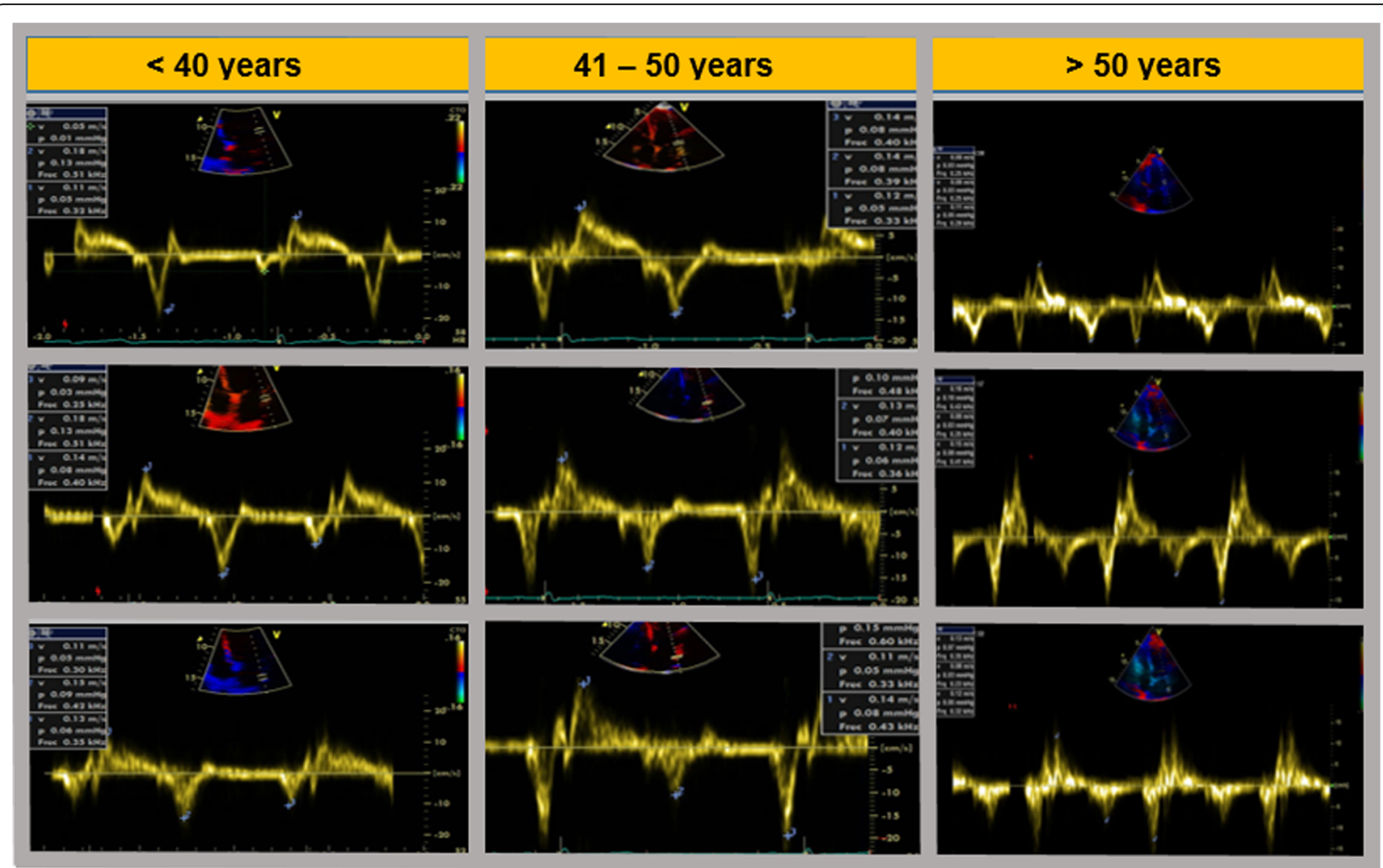

Fig. 4 Pulsed TDI at the annular level (upper row), basal LA (middle row), and mid LA (lower row), according to age groups. TDI: Tissue Doppler Imaging, LA: left atrial

between basal and mid segments when both could be satisfactorily measured, observing similar results, which we believe would minimize the measurement error determined by the cardiac movement. When evaluating only one of the walls, we did not analyze the global functionality of the LA that can be modified by the other structures not included in this study. However, it proved to be useful to detect impaired diastolic function alike SRI, which we believe is nonetheless valuable.

In our experience, the basal segment of the lateral wall of the LA can be correctly aligned in almost all of the studied subjects, while the mid segments presented, in some cases, a difficult alignment to generate an adequate curve.

There could be a limitation to apply this method in structural disease such as mitral annular calcification or atrial fibrillation.

The size of the sample was limited and the population sample used for this study has not been selected by random methods, so the informed results must be confirmed with other studies.

\section{Conclusions}

The effects of age on TDI online by spectral pulse of the LA lateral wall were assessed and normal values according to age group were reported. Age correlated with numerous parameters analyzed. Age-related changes in LA and diastolic function could be detected as early with this technique as with some parameters evaluated by SRI. Future studies are required to explore if this method could be used in lowincome places to address in part, LA and diastolic function abnormalities in other populations with established cardiovascular disease or at risk of presenting it.

\section{Supplementary information}

Supplementary information accompanies this paper at https://doi.org/10. 1186/s12947-020-00221-2.

Additional file 1: Supplemental Table 1. Analysis of the variables by age subgroups.

Additional file 2: Supplemental Table 2. Correlations with age at mid and average segments with TDI and SRI.

Additional file 3: Supplemental Table 3. Univariate and multivariate analysis.

\section{Abbreviations}

AF: Atrial fibrillation; Av: Average; BSA: Body surface area; COR: Coefficient of repeatability; DBP: Diastolic blood pressure; EF: Ejection fraction; HR: Heart rate; DTE: Deceleration time to peak E; MD: Mean difference; LA: Left atrial; LA Vol Ind: Left atrial volume index; IQR: Interquartile range; Lma: Lateral mitral annulus; LV: Left ventricular; Md: Median; SBP: Systolic blood pressure; 
SD: Standard deviation; Sma: Septal mitral annulus; TDI: Tissue Doppler Imaging; SRI: Strain Rate Imaging; Y: Years

\section{Acknowledgements}

We thank Patricia Orsi for her assistance in the translation of the document

\section{Authors' contributions}

LA and CT: Concept/design, data analysis/interpretation, drafting article, data collection, statistics, critical revision and approval of article; MC, GM, SG: data collection, critical revision of article, approval of article; AS, JL, TC: analysis and interpretation of data, critical revision of article, approval of article.

\section{Funding}

The study was conducted without external funding.

\section{Availability of data and materials}

The data and materials used in this study are available from the corresponding author on reasonable request.

\section{Ethics approval and consent to participate}

The study was approved by an Institutional Review Board and all subjects gave informed consent.

\section{Consent for publication}

Not applicable.

\section{Competing interests}

The authors declare that they have no competing interests.

\section{Author details}

${ }^{1}$ Hospital General de Agudos Dr. Cosme Argerich, Pi y Margall 750 (C1155AHD) CABA, Buenos Aires, Argentina. ${ }^{2}$ Sanatorio Clínica Modelo de Modelo de Morón, Buenos Aires, Argentina. ${ }^{3}$ Fellow of the American College of Cardiology, Washington DC, USA. ${ }^{4}$ Fellow of the American Society of Echocardiography, Durham, USA.

\section{Received: 26 February 2020 Accepted: 18 August 2020}

\section{Published online: 10 September 2020}

\section{References}

1. Boyd AC, Richards DA, Marwick T, Thomas L. Atrial strain rate is a sensitive measure of alterations in atrial phasic function in healthy ageing. Heart. 2011;97(18):1513-9. https://doi.org/10.1136/heartjnl-2011-300134.

2. Rosca M, Lancellotti $P$, Popescu BA, Piérard LA. Left atrial function: pathophysiology, echocardiographic assessment, and clinical applications. Heart. 2011;97(23):1982-9. https://doi.org/10.1136/heartjnl-2011-300069.

3. Bui AL, Horwich TB, Fonarow GC. Epidemiology and risk profile of heart failure. Nat Rev Cardiol. 2011;8(1):30-41. https://doi.org/10.1038/nrcardio. 2010.165.

4. Hees PS, Fleg JL, Dong SJ, Shapiro EP. MRI and echocardiographic assessment of the diastolic dysfunction of normal aging: altered LV pressure decline or load? Am J Physiol Heart Circ Physiol. 2004;286(2):H782-8. https:// doi.org/10.1152/ajpheart.01092.2002.

5. Abhayaratna WP, Fatema K, Barnes ME, Seward JB, Gersh BJ, Bailey KR, et al. Left atrial reservoir function as a potent marker for first atrial fibrillation or flutter in persons $\geq 65$ years of age. Am J Cardiol. 2008;101:1626-9. https://doi.org/10.1016/j.amjcard.2008.01.051.

6. Vasan RS, Larson MG, Levy D, Galderisi M, Wolf PA, Benjamin EJ. Doppler transmitral flow indexes and risk of atrial fibrillation (the Framingham heart study). Am J Cardiol. 2003;91:1079-83. https://doi.org/10.1016/S00029149(03)00152-8.

7. Hirose T, Kawasaki M, Tanaka R, Ono K, Watanabe T, Iwama M, et al. Left atrial function assessed by speckle tracking echocardiography as a predictor of new-onset non-valvular atrial fibrillation: results from a prospective study in 580 adults. Eur Heart J Cardiovasc Imaging. 2012;13(3):243-50. https://doi. org/10.1093/ejechocard/jer251.

8. Ancona R, Comenale Pinto S, Caso P, Di Salvo G, Severino S, D'Andrea A et al. Two-dimensional atrial systolic strain imaging predicts atrial fibrillation at 4-year follow-up in asymptomatic rheumatic mitral stenosis. J Am Soc Echocardiogr. 2013;26(3):270-7. https://doi.org/10.1016/j.echo.2012.11.016.
9. Kurt M, Wang J, Torre-Amione G, Nagueh SF. Left atrial function in diastolic heart failure. Circ Cardiovasc Imaging. 2009:2:10-5. https://doi.org/10.1161/ CIRCIMAGING.108.813071.

10. Gottdiener JS, Kitzman DW, Aurigemma GP, Arnold AM, Manolio TA. Left atrial volume, geometry, and function in systolic and diastolic heart failure of persons $\geq 65$ years of age (the cardiovascular health study). Am J Cardiol. 2006;97:83-9. https://doi.org/10.1016/j.amjcard.2005.07.126.

11. Melenovsky V, Hwang SJ, Redfield MM, Zakeri R, Lin G, Borlaug BA. Left atrial remodeling and function in advanced heart failure with preserved or reduced ejection fraction. Circ Heart Fail. 2015;8(2):295-303. https://doi.org/ 10.1161/CIRCHEARTFAILURE.114.001667.

12. Vieira MJ, Teixeira R, Gonçalves L, Gersh BJ. Left atrial mechanics: echocardiographic assessment and clinical implications. J Am Soc Echocardiogr. 2014;27(5):463-78. https://doi.org/10.1016/j.echo.2014.01.021.

13. Hoit BD. Assessment of left atrial function by echocardiography: novel insights. Curr Cardiol Rep. 2018;20(10):96. https://doi.org/10.1007/s11886018-1044-1.

14. Argento LV, Travetto CM, Colicigno M, Gentile S, Salvati A, Lax J, Cianciulli T. Tissue Doppler imaging of the atrial lateral wall: correlation with atrial strain rate and parameters of diastolic function. Echocardiography. 2019;36(7): 1282-9. https://doi.org/10.1111/echo.14394.

15. Lang RM, Mor-Avi V, Afilalo J, Armstrong A, Ernande L, et al. Recommendations for cardiac chamber quantification by echocardiography in adults: an update from the American Society of Echocardiography and the European Association of Cardiovascular Imaging. Eur Heart J Cardiovasc Imaging. 2015;16(3):233-70. https://doi.org/10.1093/ehjci/jev014.

16. Nagueh SF, Smiseth OA, Appleton CP, Byrd BF 3rd, Dokainish H, Edvardsen $T$, et al. Recommendations for the evaluation of left ventricular diastolic function by echocardiography: an update from the American Society of Echocardiography and the European Association of Cardiovascular Imaging. J Am Soc Echocardiogr. 2016;29(4):277-314. https://doi.org/10.1016/j.echo. 2016.01.011

17. Pérez-Paredes M, Gonzálvez M, Ruiz Ros JA, Giménez DM, Carnero A, Carrillo A, et al. Evaluación de las velocidades de pared de la aurícula izquierda mediante Doppler pulsado tisular. Una nueva aproximación al estudio de la función auricular. Rev Esp Cardiol. 2004;57(11):1059-65.

18. Bland JM, Altman DG. Statistical methods for assessing agreement between two methods of clinical measurement. Lancet. 1986;1:307-10.

19. Blume GG, Mcleod CJ, Barnes ME, Seward JB, Pellikka PA, Bastiansen PM, et al. Left atrial function: physiology, assessment, and clinical implications. Eur J Echocardiogr. 2011;12(6):421-30. https://doi.org/10.1093/ejechocard/ jeq175.

20. Boyd AC, Schiller NB, Leung D, Ross DL, Thomas L. Atrial dilation and altered function are mediated by age and diastolic function but not before the eighth decade. JACC Cardiovasc Imaging. 2011;4(3):234-42. https://doi. org/10.1016/j.jcmg.2010.11.018

21. Dugo C, Rigolli M, Rossi A, Whalley G. Assessment and impact of diastolic function by echocardiography in elderly patients. J Geriatr Cardiol. 2016; 13(3):252-60. https://doi.org/10.11909/j.issn.1671-5411.2016.03.008.

22. Fleg JL, Strait J. Age-associated changes in cardiovascular structure and function: a fertile milieu for future disease. Heart Fail Rev. 2012;17(4-5):54554. https://doi.org/10.1007/s10741-011-9270-2.

23. Obas V, Vasan RS. The aging heart. Clin Sci (Lond). 2018;132(13):1367-82. https://doi.org/10.1042/CS20171156.

24. Upadhya B, Taffet GE, Cheng CP, Kitzman DW. Heart failure with preserved ejection fraction in the elderly: scope of the problem. J Mol Cell Cardiol. 2015;83:73-87. https://doi.org/10.1016/j.yjmcc.2015.02.025.

25. Hadid C, González JL, Abello M, Muratore C, Giniger A, Dubner S, et al. Consenso de fibrilación auricular. Sociedad Argentina de Cardiología. Área de Consensos y Normas. Rev Argent Cardiol. 2015;83(Supl 1):1-28.

26. Doval H, Borracci R, Tajer, et al. Consenso de Insuficiencia Cardíaca Crónica. Sociedad Argentina de Cardiología. Área de Consensos y Normas. Rev Argent Cardiol. 2016;84(Suplemento 3):1-50

27. Heidenreich PA, Albert NM, Allen LA, Bluemke DA, Butler J, Fonarow G, et al; American Heart Association Advocacy Coordinating Committee; Council on Arteriosclerosis, Thrombosis and Vascular Biology; Council on Cardiovascular Radiology and Intervention; Council on Clinical Cardiology; Council on Epidemiology and Prevention; Stroke Council. Forecasting the impact of heart failure in the United States: a policy statement from the American Heart Association. Circ Heart Fail. 2013;6(3):606-619. https://doi.org/10.1161/ HHF.0b013e318291329a. 
28. Steenman M, Lande G. Cardiac aging and heart disease in humans. Biophys Rev. 2017;9(2):131-7. https://doi.org/10.1007/s12551-017-0255-9.

29. World Health Organization. Compendium of innovative health technologies for low-resource settings: assistive devices, eHealth solutions, medical devices. Geneva: World Health Organization. WHO; 2014. https://apps.who. int/iris/handle/10665/108781.

30. Inaba Y, Yuda, Kobayashi N, Hashimoto A, Uno K, Nakata T, et al. Strain rate imaging for noninvasive functional quantification of the left atrium: comparative studies in controls and patients with atrial fibrillation. J Am Soc Echocardiogr. 2005;18(7):729-36. https://doi.org/10.1016/j.echo.2004.12.005.

31. Wang T, Wang M, Fung JW, Yip GW, Zhang Y, Ho PP, et al. Atrial strain rate echocardiography can predict success or failure of cardioversion for atrial fibrillation: a combined transthoracic tissue Doppler and transoesophageal imaging study. Int J Cardiol. 2007;114:202-9.

32. Mondillo S, Cameli M, Caputo ML, Lisi M, Palmerini E, Padeletti M, Ballo PJ. Early detection of left atrial strain abnormalities by speckle-tracking in hypertensive and diabetic patients with normal left atrial size. J Am Soc Echocardiogr. 2011;24(8):898-908. https://doi.org/10.1016/j.echo.2011.04.014.

33. Thomas $L$, Levett $K$, Boyd $A$, et al. Changes in regional left atrial function with aging: evaluation by Doppler tissue imaging. Eur J Echocardiogr. 2003; 4:92-100. https://doi.org/10.1053/euje.2002.0622.

34. Sun JP, Yang Y, Guo R, Wang D, Lee AP, Wang XY, et al. Left atrial regional phasic strain, strain rate and velocity by speckle-tracking echocardiography: normal values and effects of aging in a large group of normal subjects. Int J Cardiol. 2013;168(4):3473-9. https://doi.org/10.1016/j.jijcard.2013.04.167.

35. Yoshida Y, Nakanishi K, Daimon M, Ishiwata J, Sawada N, Hirokawa M, et al. Alteration of Cardiac Performance and Serum B-Type Natriuretic Peptide Level in Healthy Aging. J Am Coll Cardiol. 2019;74(14):1789-800. https://doi. org/10.1016/j.jacc.2019.07.080

36. Meel R, Khandheria BK, Peters F, Libhaber E, Nel S, Essop MR. Effects of age on left atrial volume and strain parameters using echocardiography in a normal black population. Echo Res Pract. 2016;3(4):115-23. https://doi.org/ 10.1530/ERP-16-0038.

37. Thorstensen A, Dalen H, Amundsen BH, Aase SA, Stoylen A. Reproducibility in echocardiographic assessment of the left ventricular global and regiona function, the HUNT study. Eur J Echocardiogr. 2010:149-56. https://doi.org/ 10.1093/ejechocard/jep188

38. Mor-Avi V, Lang RM, Badano LP, Belohlavek M, Cardim NM, Derumeaux G, et al. Current and evolving echocardiographic techniques for the quantitative evaluation of cardiac mechanics: ASE/EAE consensus statement on methodology and indications endorsed by the Japanese Society of Echocardiography. J Am Soc Echocardiogr. 2011;24(3):277-313. https://doi. org/10.1016/j.echo.2011.01.015.

39. Morris DA, Takeuchi M, Krisper M, Köhncke C, Bekfani T, Carstensen T, et al. Normal values and clinical relevance of left atrial myocardial function analysed by speckle-tracking echocardiography: multicentre study. Eur Heart J Cardiovasc Imaging. 2015;16(4):364-72. https://doi.org/10.1093/ehjci/ jeu219.

40. Cianciulli TF, Saccheri MC, Lax JA, Bermann AM, Ferreiro DE. Two-dimensional speckle tracking echocardiography for the assessment of atrial function. World J Cardiol. 2010;2(7):163-70. https://doi.org/10.4330/wjc.v2.17.163.

41. Deschle HA, Gantesti J, Culaciati G, Casso N, Alfie L, Gingins M, et al. Análisis de la deformación auricular longitudinal: alteraciones precoces en hipertensos jóvenes controlados. Rev Argent Cardiol. 2014;82(2):126-32. https://doi.org/10.7775/rac.es.v82.i2.2345.

\section{Publisher's Note}

Springer Nature remains neutral with regard to jurisdictional claims in published maps and institutional affiliations.

Ready to submit your research? Choose BMC and benefit from:

- fast, convenient online submission

- thorough peer review by experienced researchers in your field

- rapid publication on acceptance

- support for research data, including large and complex data types

- gold Open Access which fosters wider collaboration and increased citations

- maximum visibility for your research: over $100 \mathrm{M}$ website views per year

At BMC, research is always in progress.

Learn more biomedcentral.com/submissions 